\title{
Publisher's Note: Sub-Shot-Noise Transmission Measurement Enabled by Active Feed-Forward of Heralded Single Photons [Phys. Rev. Applied 8, 014016 (2017)]
}

J. Sabines-Chesterking, R. Whittaker, S. K. Joshi, P. M. Birchall, P. A. Moreau, A. McMillan, H. V. Cable, J. L. O'Brien, J. G. Rarity, and J. C. F. Matthews

(Received 5 October 2017; published 13 October 2017)

DOI: 10.1103/PhysRevApplied.8.049902

This paper was published online on 17 July 2017 with an omission in the Acknowledgments. On page 5, the last sentence of the Acknowledgments should read as "J. C. F. M. and J. G. R. acknowledge fellowship support from the Engineering and Physical Sciences Research Council under Grant Code No. EP/M024385/1". The Acknowledgments have been corrected as of 6 October 2017. The Acknowledgments are incorrect in the printed version of the journal.

Published by the American Physical Society under the terms of the Creative Commons Attribution 4.0 International license. Further distribution of this work must maintain attribution to the author(s) and the published articles title, journal citation, and DOI. 